This item was submitted to Loughborough's Research Repository by the author.

Items in Figshare are protected by copyright, with all rights reserved, unless otherwise indicated.

\title{
Raman spectroscopy study of the transformation of the carbonaceous skeleton of a polymer-based nanoporous carbon along the thermal annealing pathway
}

\section{PLEASE CITE THE PUBLISHED VERSION}

http://dx.doi.org/10.1016/j.carbon.2014.12.098

\section{PUBLISHER}

(C) Elsevier Ltd.

\section{VERSION}

AM (Accepted Manuscript)

\section{PUBLISHER STATEMENT}

This work is made available according to the conditions of the Creative Commons Attribution-NonCommercialNoDerivatives 4.0 International (CC BY-NC-ND 4.0) licence. Full details of this licence are available at: https://creativecommons.org/licenses/by-nc-nd/4.0/

\section{LICENCE}

CC BY-NC-ND 4.0

\section{REPOSITORY RECORD}

Hu, Cheng, Saeid Sedghi, Ana Silvestre-Albero, Gunther G. Andersson, Anirudh Sharma, Phillip Pendleton, Francisco Rodriguez-Reinoso, Katsumi Kaneko, and Mark J. Biggs. 2019. "Raman Spectroscopy Study of the Transformation of the Carbonaceous Skeleton of a Polymer-based Nanoporous Carbon Along the Thermal Annealing Pathway". figshare. https://hdl.handle.net/2134/18660. 


\title{
Raman Spectroscopy Study of the Transformation of the Carbonaceous Skeleton of a Polymer-based Nanoporous Carbon Along the Thermal Annealing Pathway
}

Cheng $\mathrm{Hu}^{\mathrm{a}}$, Saeid Sedghi ${ }^{\mathrm{a}}$, Ana Silvestre-Albero ${ }^{\mathrm{b}}$, Gunther G. Andersson ${ }^{\mathrm{c}}$, Anirudh Sharma ${ }^{\mathrm{c}}$, Phillip Pendleton ${ }^{\mathrm{d}, \mathrm{e}}$, Francisco Rodríguez-Reinoso ${ }^{\mathrm{b}}$, Katsumi Kaneko ${ }^{\mathrm{f}}$ and Mark J. Biggs ${ }^{\mathrm{a}, \mathrm{g}, *}$

${ }^{a}$ School of Chemical Engineering, The University of Adelaide, SA 5005, Australia.

b Laboratorio de Materiales Avanzados, Departamento de Química Inorgánica, Universidad de Alicante, Apartado 99 E-03080, Spain.

c Flinders Centre for NanoScale Science and Technology, Flinders University, PO Box 2100, Adelaide SA 5001, Australia

${ }^{\mathrm{d}}$ Ian Wark Research Institute, University of South Australia, SA 5095, Australia.

e Sansom Institute, University of South Australia, SA 5001, Australia.

${ }^{\mathrm{f}}$ Research Center for Exotic Nano Carbons, Shinshu University, Nagano 380-8553, Japan.

${ }^{g}$ School of Science, Loughborough University, Leicestershire, UK LE11 3TU.

\begin{abstract}
We report a multi-wavelength Raman spectroscopy study of the structural changes along the thermal annealing pathway of a poly(furfuryl alcohol) (PFA) derived nanoporous carbon (NPC). The Raman spectra were deconvoluted utilizing G, D, D', A and TPA bands. The appropriateness of these deconvolutions was confirmed via recovery of the correct dispersive behaviours of these bands. It is proposed that the $I_{\mathrm{D}} / I_{\mathrm{G}}$ ratio is composed of two parts: one associated with the extent of graphitic crystallites (the Tuinstra-Koenig relationship), and a second related to the inter-defect distance. This model was used to successfully determine the variation of the in-plane size and intra-plane defect density along the annealing pathway. It is proposed that the NPC skeleton evolves along the annealing pathway in two stages: below $1600^{\circ} \mathrm{C}$ it was dominated by a reduction of in-plane defects with a minor crystallite growth, and above this temperature growth of the crystallites accelerates as the in-plane defect density approaches zero. A significant amount of transpolyacetylene (TPA)-like structures was found to be remaining even at $2400^{\circ} \mathrm{C}$. These may be responsible for resistance to further graphitization of the PFA-based carbon at higher temperatures.
\end{abstract}

E-mail: m.biggs@lboro.ac.uk (Mark J. Biggs) 


\section{Introduction}

The non-crystalline nature of nanoporous carbons (NPCs) makes characterisation of their carbonaceous skeleton a challenge. It is generally accepted that the skeleton is largely composed of nanometre-sized $s p^{2}$-dominated building blocks [1-6]. Careful diffraction [5, 7-10] and transmission electron microscopy (TEM) [2, 3, 11] studies suggest these building blocks could be characterised as defective graphene-like layers with limited stacking order. Apart from the abundance of inter-layer boundaries due to their nanoscale size, intra-layer defects have also been observed in recent atomic-resolution electron microscopy studies [12-14], including in the form of non-hexagonal rings. Structural models, that captures microporosity as well as defective carbonaceous skeleton have been proposed of this material $[1,9,10,12,15,16]$ although there is still debate over their validity [1]. A quantitative understanding of this defective structure is important for tailoring NPCs to have desired characteristics in the contexts of adsorption [14], thermal [17] and electrical [18] conductivity, and Li-ion capacity [19].

Although electron microscopy techniques have played a major role in the study of structural defects within NPCs, they are much less useful when a quantitative analysis representative of the bulk volume is required. Raman spectroscopy, on the other hand, is sensitive to structural defects in bulk-scale samples. It has, for example, long been used to determine the in-plane size of the $s p^{2}$ building blocks $\left(L_{\mathrm{a}}\right)$ from the ratio of the intensities of the $\mathrm{D}$ and $\mathrm{G}$ bands $\left(I_{\mathrm{D}} / I_{\mathrm{G}}\right)$, the two most outstanding features in NPC Raman spectra. It is now known that the Tuinstra-Koenig relationship [20] (and its recent modification [21, 22]) used to achieve this has its origins in the link between the $\mathrm{D}$ band and edge sites of the graphenic building blocks [23] on the one hand, and the dependence of the $G$ band on the building blocks in their entirety on the other. This and the fact that the relationships were derived using data for highly graphitic materials that likely contain low levels of intra-layer defects suggests care should be exercised in their application to NPCs. One possibility to address this concern is to use the relationship between the $I_{\mathrm{D}} / I_{\mathrm{G}}$ ratio and intraplane point-like defects derived recently [24-27] in conjunction with the Tuinstra-Koenig relationship. This has not, however, been done to date as far as the authors are aware.

Theoretical studies [28, 29] have indicated that structural details of carbon materials are also carried in other parts of the Raman spectrum. Of interest here are those that have been experimentally observed for disordered carbons and are thought to be related to defects, namely the D' [22, 30-34], A [35-41] and TPA [40-42] bands. Similar to the $\mathrm{D}$ band, the $\mathrm{D}^{\prime}$ band is caused by defect-induced breaking of translational symmetry [32]. The origins of the A band, on the other hand, is less well understood. Early studies attributed it to the 'amorphous phase' (i.e. non-crystalline $s p^{3}$-dominated carbon) [35-37], whilst more recent theoretical and experimental studies [38-41] suggested it may come from non-hexagonal ring defects in the $s p^{2}$ system. The TPA band has been linked to both 
$s p^{2}$-based transpolyacetylene-like chains (see Fig. 1) at layer edges [42] and, more recently, to zigzag edges [40, 41], although this assignment is questionable given the contrast between the abundance of zig-zag edges in these materials and the relatively low intensity of TPA bands that appear in their Raman spectra.

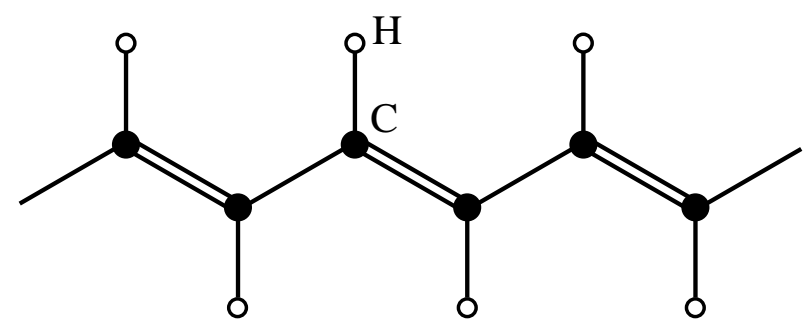

Fig. 1. Transpolyacetylene-like structure.

Evidence [39] has been found for the co-existence of all five Raman bands discussed above in NPCs. A thorough interpretation of NPC Raman spectra should, therefore, in principle involve consideration of all these bands during deconvolution (this is not to say that all may ultimately be included in a deconvolution). The use of multi-wavelength laser sources can also help improve deconvolution reliability as the fitted results can be checked against the expected excitation energy dispersive behaviour [23, 31, 32, 40-43].

In this paper we report a multi-band/multiwavelength Raman spectroscopy investigation of the change in the defects of a nominally nongraphitizing NPC along an annealing pathway. The laser sources used range from the UV (266 $\mathrm{nm})$ to the near-IR $(785 \mathrm{~nm})$, and the first order spectra obtained using these sources were deconvoluted successfully by considering the five Raman bands discussed above. The success of these deconvolutions was validated against the expected energy dispersive behaviour as well as XRD-derived data for the carbons. The relationship between the $I_{\mathrm{D}} / I_{\mathrm{G}}$ ratio and intraplane point-like defects [24-27] was then used in conjunction with the Tuinstra-Koenig relationship to derive both the cluster size and intra-plane defect density. This relationship was tested by deliberately introducing point-like defects into selected samples using controlled $\mathrm{Ar}^{+}$ion bombardment. The origins of the A band was also investigated.

\section{Materials and methods}

\subsection{Sample preparation}

In order to reduce as much as possible experimental uncertainties, the base carbon studied here, termed $\mathrm{C} 45 \mathrm{SCO}_{2}$ hereafter [44], was derived from a furfuryl alcohol (FA) precursor using a carefully controlled process. The full details of this process may be found elsewhere [44] but are briefly outlined here for convenience. The as-received FA was vacuumdistilled to remove any contaminants before being mixed under an inert atmosphere with oxalic acid dehydrate as a polymerization catalyst. Small batches of the mixture were then heated in a horizontal quartz tube-furnace to $150^{\circ} \mathrm{C}$ under continuous argon flow before being soaked for 1 hour to bring about polymerization. Carbonization was then done under argon by further increasing the temperature to $800^{\circ} \mathrm{C}$ before being soaked for 2 hours. The cooled char was then broken up into chunks using a clean zirconia press before being ball-milled and sieved 
to obtain a powder with a particle size distribution of 38-106 $\mu \mathrm{m}$. The powdered material was then activated to $45 \%$ conversion using $\mathrm{CO}_{2}$ at $805^{\circ} \mathrm{C}$ for 48 hours. It has been shown that this slow activation protocol leads to homogeneous particles [44]. The carbon was kept in glass vials under an argon atmosphere until used.

A range of NPCs were derived from the ${\mathrm{C} 45 \mathrm{SCO}_{2}}_{2}$ carbon by subjecting it to heating under an argon atmosphere at 1000, 1600, 2000 and $2400^{\circ} \mathrm{C}$; these carbons are referred to henceforth as C1000, C1600, C2000 and C2400. The C1000 material was produced under an Ar (99.9\%) atmosphere using a quartz tube-furnace (Lindberg, USA) with a heating rate of $10^{\circ} \mathrm{C} / \mathrm{min}$ and soak time of 2 hours. All the remaining annealed products were produced under an $\mathrm{Ar}$ (99.999\%) atmosphere using a graphite furnace (Xerion, Germany) with a heating rate of $15^{\circ} \mathrm{C} / \mathrm{min}$ up to $1500^{\circ} \mathrm{C}$ and $10^{\circ} \mathrm{C} / \mathrm{min}$ thereafter before being soaked for 1 hour.

Two final carbons, denoted hereafter by

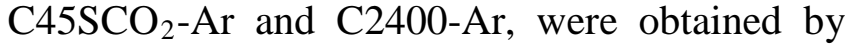
$\mathrm{Ar}^{+}$ion bombardment of the base $\mathrm{C}_{4} 5 \mathrm{SCO}_{2}$ and C2400 carbons respectively. This involved the particular carbon first being mounted onto a $1 \times 1$ cm silicon substrate using double-sided sticky tape with a copper interlayer before being inserted into an ultra-high vacuum system (SPECS, Germany) with a base pressure of a few $10^{-10}$ mbar. The sample was then uniformly bombarded with $1.6 \times 10^{15} \mathrm{Ar}^{+}$ions produced at $1000 \mathrm{eV}$ and $0.04 \mu \mathrm{A}$.

\subsection{XRD analysis}

The base and thermally annealed carbons were subject to XRD analysis using a Miniflex 600 bench-top diffractometer (Rigaku, Japan) equipped with $40 \mathrm{kV} \mathrm{Cu} \mathrm{K \alpha} \mathrm{X-ray} \mathrm{source.} \mathrm{The}$ diffraction patterns were collected over the $2 \theta$ range of $5^{\circ}$ to $100^{\circ}$ at a scanning rate of $10^{\circ}$ per minute and $0.02^{\circ}$ per step.

Although use of the graphitic crystallite model [45] as a basis for analysis of NPC XRD diffraction patterns is questionable [46], we report such an analysis here given the Tuinstra-Koenig relationship is based on high graphitic materials. We have used the 10 and 002 peaks in the diffraction patterns to obtain the average in-plane extent, $L_{a}$, and height, $L_{c}$, of the crystallites respectively via the Scherrer equation [45]

$L_{i}=\frac{K_{i} \lambda}{B_{i} \cos \theta_{i}}$

where $\lambda$ is the $\mathrm{X}$-ray wavelength $(0.154 \mathrm{~nm}$ for the $\mathrm{Cu} \mathrm{K} \alpha$ radiation used here), $\theta_{i}$ and $B_{i}$ are the scattering angle and full width at half maximum (FWHM) values for the relevant peak, respectively, and $K_{a}=1.84$ and $K_{c}=0.89$.

The average spacing between graphenic layers was also estimated using the Bragg equation

$d_{002}=\frac{\lambda}{2 \sin \theta_{002}}=\frac{1}{k_{002}}$

where $k_{002}$ is the wave vector magnitude associated with the 002 peak, which can be determined by first subtracting the small angle scattering intensity from the spectra and then fitting a Gaussian function to the peak. 


\subsection{Raman analysis}

Raman spectroscopy was performed on a Labram HR Evolution spectrometer (Horiba Jobin-Ivon, France) equipped with Synapse charged coupled device detection system (Horiba Jobin-Ivon, France). Four laser sources were used: a near-IR (NIR) laser (785 nm, $1.58 \mathrm{eV}$ ), two visible lasers (633 nm, $1.96 \mathrm{eV} ; 532 \mathrm{~nm}, 2.33 \mathrm{eV}$ ) and an UV laser (266 nm, $4.66 \mathrm{eV})$. Objective lenses of 50× and $40 \times$ magnification were used for the visible/NIR and UV lasers respectively. Low laser powers (15 mW for visible/NIR and $10 \mathrm{~mW}$ for UV) were used to avoid sample damage due to over-heating. The materials were carefully examined after analysis and no visible damage was found.

In each Raman measurement, a thin layer of sample was spread onto a glass substrate and then mounted in to a triple-axis sample stage. Spectra were collected in mapping mode using a step size of $6 \mu \mathrm{m}$ in both $\mathrm{X}$ and $\mathrm{Y}$ directions over $30 \times 30$ $\mu \mathrm{m}$ areas. Spectra were collected using an exposure time of 3 seconds. A total of 36 spectra were collected from each mapping, and the sum of these was used for each carbon sample/laser source combination. No significant variation was found among the 36 spectra in one collection as well as scans on different particles of one sample for test purpose.

All Raman spectra were fitted with combinations of G, D, D', A and TPA bands. The initial positions of the Raman bands were specified by adopting the values reported for graphenes and nanographites and also considering their excitation energy dispersion behaviours [23, 31, 32, 40-43]. The fitting was done using the Levenberg-Marquardt algorithm as implemented in Origin Pro 9.0 (OriginLab Corporation, US). The position, width and area of each band were varied simultaneously in the fitting. A total of 50000 iterations were done for each fit. At least 10 fits with reduced $\chi^{2}$ [47] values between 1.1 and 1.5 were obtained for each spectrum analysed $\left(\chi^{2}\right.$ values in the range of 1-3 indicate good fits [48]). The final band parameter values were the average of the ten best fits; standard deviations were also evaluated from these fits.

\section{Results and Discussion}

\subsection{XRD analysis}

Fig. 2 shows the XRD patterns of the base carbon $\left(\mathrm{C}_{\left.45 \mathrm{SCO}_{2}\right)}\right)$ as well as the annealed products. The 002, 10 and 11 peaks, which are commonly found for NPCs [1, 46], exist for all samples. Although the 004 peak is absent from the base and C1000 carbons, it appears in the C1600 material and grows along the annealing pathway. A small high graphitic component $\left(2 \theta=26.5^{\circ}\right.$, indicated by a red arrow in Fig. 2) also similarly appears and grows along the pathway.

Both the 10 and 11 peaks show increasing intensity and narrowing along the annealing pathway, indicating improving in-plane coherence length and atomic ordering. Similarly, the 002 peak narrows and grows in intensity between the base and C2400 material, where it is quite sharp and located at $2 \theta=26.5^{\circ}$ in line with a high graphitic stacking phase [49]. These results 
collectively suggest increasing graphitization of the carbon skeleton along the annealing.

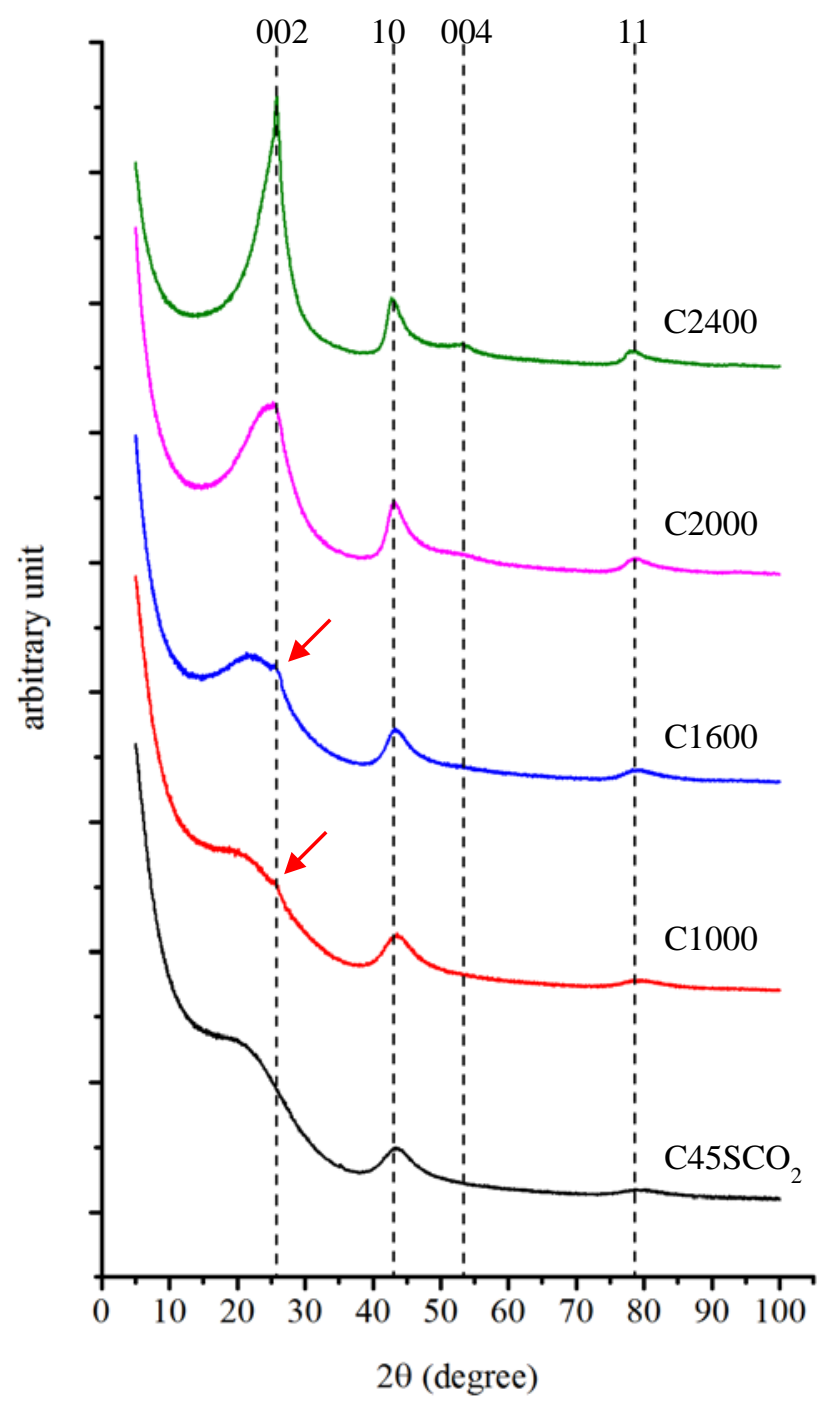

Fig. 2. XRD patterns of base carbon and annealed products derived from it.

The average extents of the graphitic crystallites, $L_{\mathrm{a}}$ and $L_{\mathrm{c}}$, and average inter-layer spacing, $d_{002}$, evaluated from the XRD scattering patterns are plotted in Fig. 3 against the annealing temperature. The average inter-layer spacing of $\mathrm{C} 45 \mathrm{SCO}_{2}$ is about $0.44 \mathrm{~nm}, 32 \%$ higher than that of graphite. Together with the broadness of the 002 peak, it reflects the lack of inter-layer ordering in this material. The inter-layer spacing steadily decreases along the annealing pathway until it reaches $0.34 \mathrm{~nm}$ at $2400^{\circ} \mathrm{C}$, just slightly greater than that of graphite. Fig. 3(b) and (c) show, on the other hand, that the crystallite extents steadily grow along the annealing
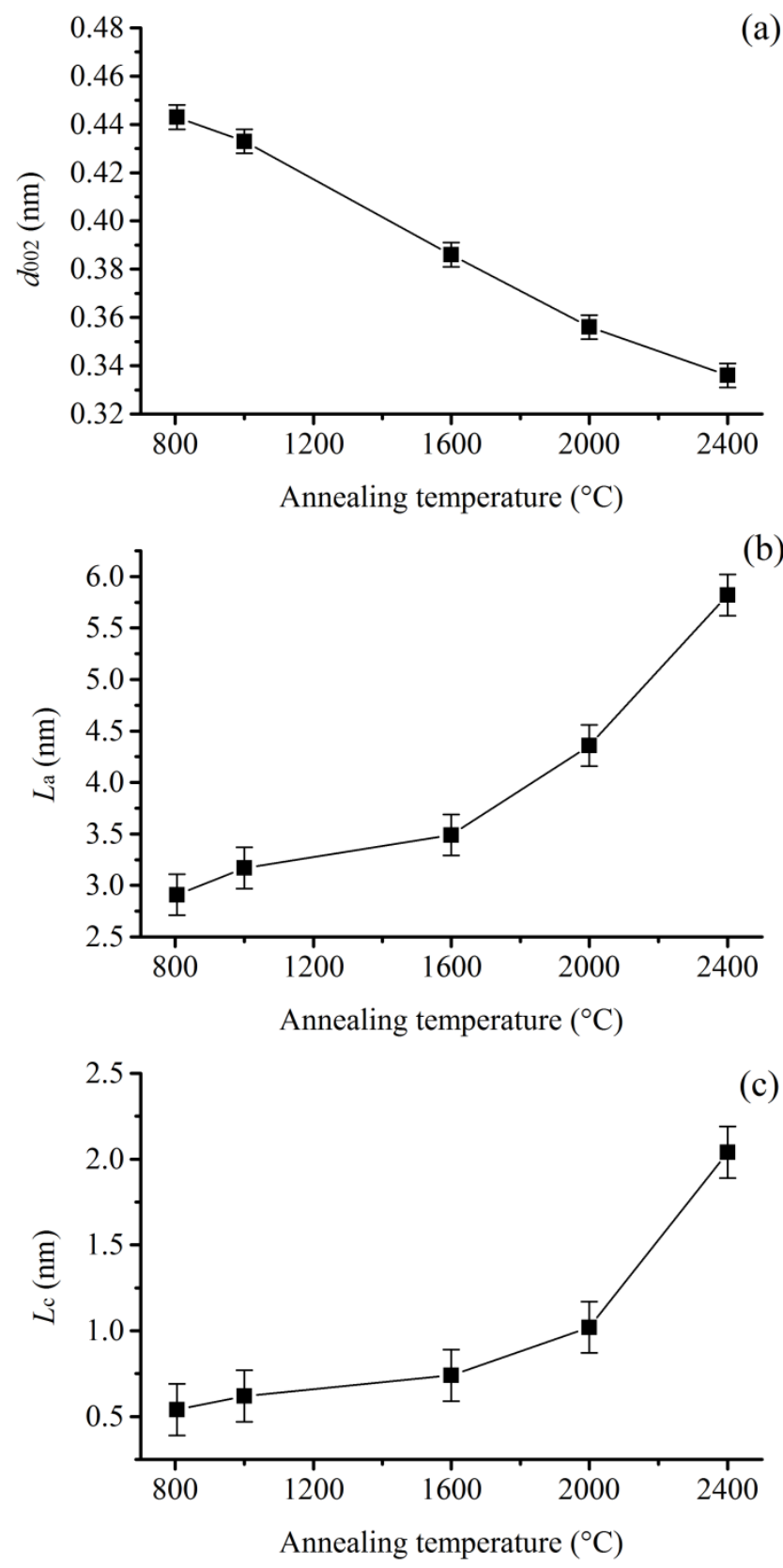

Fig. 3. Change of the graphitic crystallite parameters along annealing pathway: (a) average inter-layer spacing; (b) in-plane extent; and (c) normal-to-plane extent. The values for the base carbon are plotted for reference at the temperature where activation took place. Error bars are one standard deviation from five repeat measurements. pathway. The height of the crystallites in the C2400 material grows to around 4 times that in the base material whilst the in-plane extent is 
nearly double. Despite the significant growth in size of the crystallites, they are still modestly sized as one may expect from a non-graphitizing carbon [50]. Interestingly, although the inter-layer spacing drops in a linear manner, the rate of growth in the crystallite extents is retarded up to $1600^{\circ} \mathrm{C}$ compared to above this temperature, suggesting some additional resistance to crystallite growth below this temperature.

\subsection{Raman Band Analysis}

\subsubsection{Overview}

Fig. 4 shows the Raman spectra of the base carbon $\left(\mathrm{C}_{\left.45 \mathrm{SCO}_{2}\right)}\right.$ collected using the four different lasers along with their deconvolution and associated residual; all the spectra are normalized to the maximum of the intensity of the $\mathrm{G}$ band located in every case at around 1600 $\mathrm{cm}^{-1}$. The spectra for all but that obtained using the UV laser are similar in character. In addition to the $G$ band, they possess a larger feature to its left that is the D band along with a clear small shoulder on its left. Comparison of Fig. 4(a)-(d) indicates that the area under the $\mathrm{D}$ band (henceforth termed the intensity) grows relative to that of the $G$ band as the excitation energy decreases; this can be explained by the fact that the absolute cross section of the latter band is proportional to the fourth power of the energy (approximately, as we will see below) whilst that of the $\mathrm{D}$ band is independent of the energy [22]. The $\mathrm{D}$ band also upshifts with the excitation
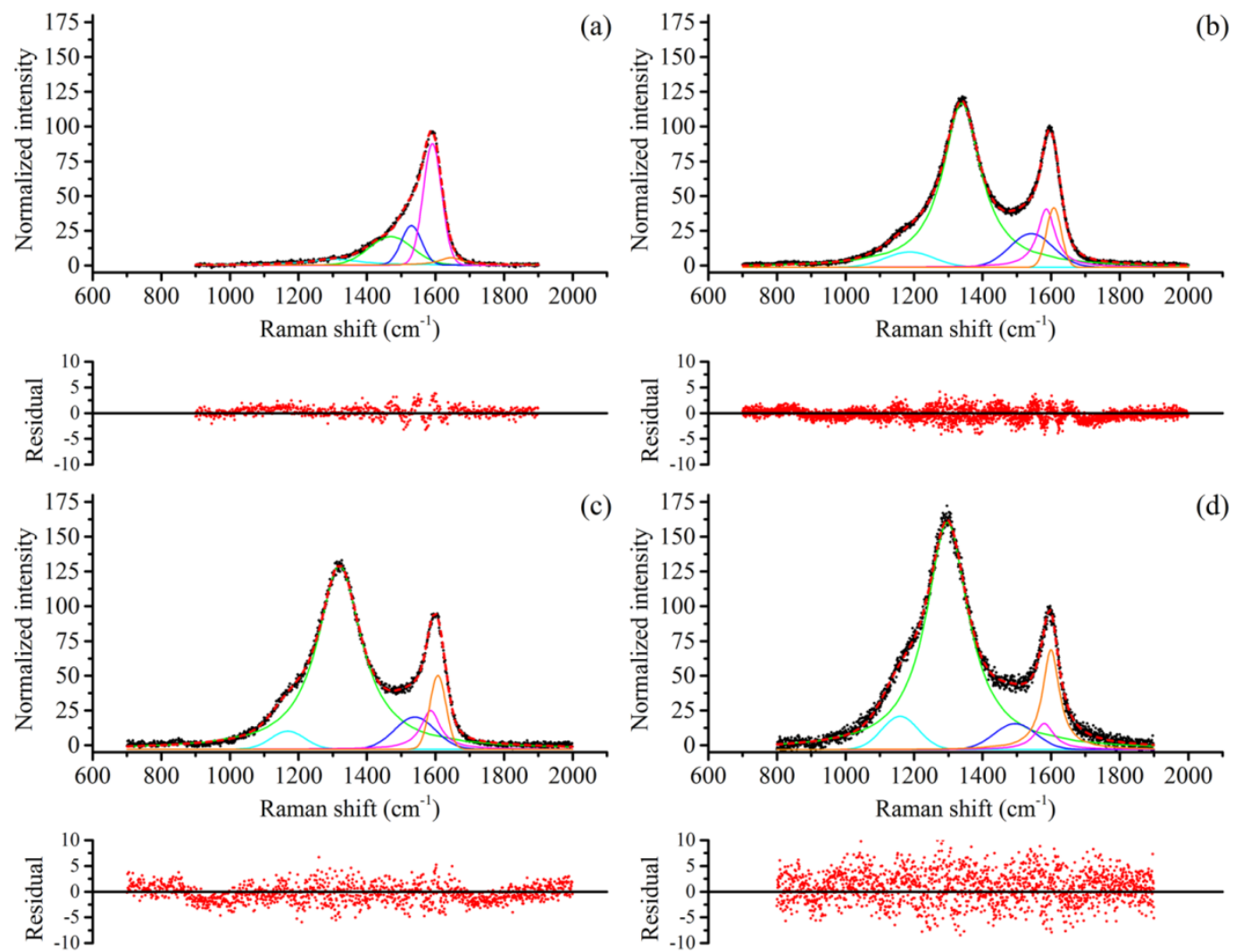

Fig. 4. Normalised Raman spectra of the $\mathrm{C} 45 \mathrm{SCO}_{2}$ carbon collected at four different excitation wavelengths, $\lambda$, (black points) and their deconvolutions using the TPA (cyan), D (green), A (blue), G (pink) and D'(orange) bands: (a) $\lambda=266 \mathrm{~nm}(4.66 \mathrm{eV})$; (b) $\lambda=532 \mathrm{~nm}$ (2.33 eV); (c) $\lambda=633 \mathrm{~nm}(1.96$ $\mathrm{eV})$; and (d) $\lambda=785 \mathrm{~nm}(1.58 \mathrm{eV})$. The overall fits to the experimental Raman spectra are shown as red dashed lines and residuals between experimental data and fits are plotted below the spectra (red points). 

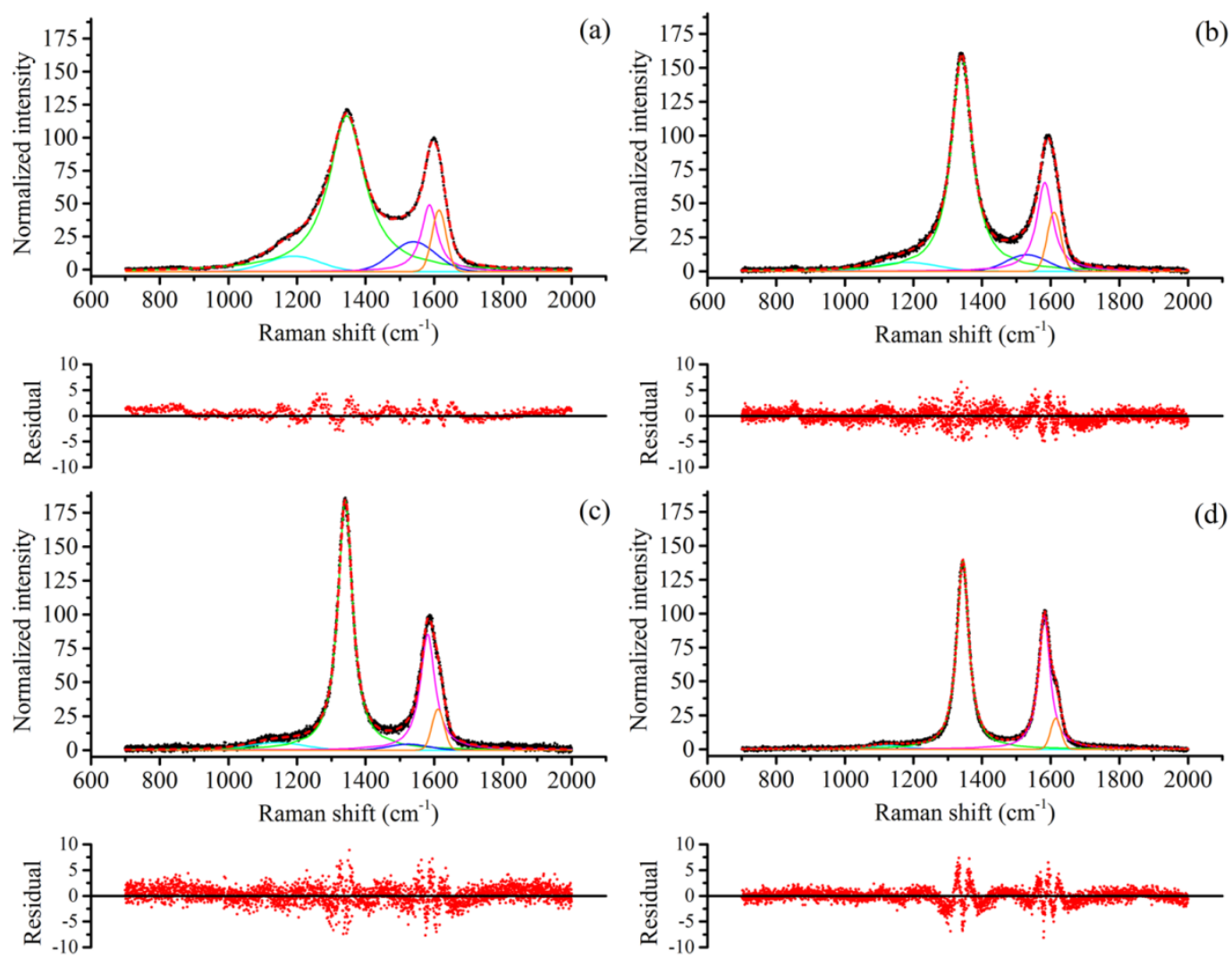

Fig. 5. Normalised Raman spectra of the carbons (black points) along the annealing pathway obtained using an excitation wavelength of $532 \mathrm{~nm}$ and their deconvolutions and associated residual (see Fig. 4 for colour scheme): (a) C1000; (b) C1600; (c) C2000; and (d) C2400.

energy, which is in line with the $50 \mathrm{~cm}^{-1}$ per eV energy-dispersive nature of the $\mathrm{D}$ band $[31,32$, 43, 51, 52]. Although the spectrum obtained using UV excitation differs from the others in that the $\mathrm{G}$ band is clearly the only dominate feature, with the $\mathrm{D}$ band being reduced to a small shoulder on its left at around $1430 \mathrm{~cm}^{-1}$, this behaviour also has its origins in the differences in energy dispersive and absolute cross-section character of the two bands.

It was found that the best fits to the experimental spectra shown in Fig. 4 were achieved by using, in addition to the $\mathrm{G}$ and $\mathrm{D}$ bands, the TPA band [40-42], which is responsible for the shoulder on the left of the D band, the A band [35-41], which contributes to the intensity between $\mathrm{G}$ and $\mathrm{D}$ band, and the D' band [22, 30-34], which is located just to the right of the $G$ band. Whilst the residual plots in Fig. 4 indicate satisfactory fits, this is confirmed below through the recovery of the correct excitation energy dependence of the TPA, D and D' band positions [22, 23, 31, 32, 40-43].

Fig. 5 shows the Raman spectra of the four carbons along the annealing pathway obtained using an excitation wavelength of $532 \mathrm{~nm}$; once again, they have been normalised using the intensity of the $\mathrm{G}$ band. It is clear from this figure that the positions of the bands are invariant with temperature. Their intensities are, however, dependent upon temperature as one may expect given the XRD analysis suggests the carbonaceous skeleton is changing along the annealing pathway. The narrowing of the $G$ and 
D bands combined with diminishing TPA and A bands, with the latter disappearing in the C2400 material, is all suggestive of an increasing degree of graphitization along the annealing pathway. Greater detail of these changes will follow below when considering the individual bands more deeply.

\subsubsection{G band}

Fig. 6(a) shows the variation of the $G$ band position along the annealing pathway for the four Raman excitation wavelengths; the differences between the variations for the different wavelengths is within the uncertainty of the data, in keeping with the non-dispersive nature of the $\mathrm{G}$ band. Whilst the trend in the figure is not unambiguous, it appears as if the $\mathrm{G}$ band position decreases along the annealing pathway towards graphite's $\mathrm{G}$ band position of $1580 \mathrm{~cm}^{-1}$. This suggests the decrease seen here reflects an increasing degree of graphitization [23, 53], in line with the XRD results presented in the previous section.

The upshift of the $G$ peak position of the base material relative to graphite is in line with that seen in studies of other $s p^{2}$-dominated carbonaceous materials like pyrolytic chars [31, 43, 54, 55], carbon blacks [37, 56], activated carbons [36, 57], glassy carbons [43, 51] and carbon fibres [58, 59]. The upshift is not, however, in keeping with that seen for carbon materials with significant $s p^{3}$ content, where shifts well beyond $1600 \mathrm{~cm}^{-1}$ have been observed [52, 60-62]. Ferrari et al [52], for example, observed the $G$ band position of a tetrahedral amorphous carbon to decrease from $1690 \mathrm{~cm}^{-1}$ at $88 \% \mathrm{sp}^{3}$ content to $1585 \mathrm{~cm}^{-1}$ at zero content. Comparing this with the $\mathrm{G}$ band positions of the carbons here suggests they contain little, if any, $s p^{3}$ carbon. This is also confirmed by the absence of the $\mathrm{T}$ band in the UV spectra [62] for the carbons studied here.
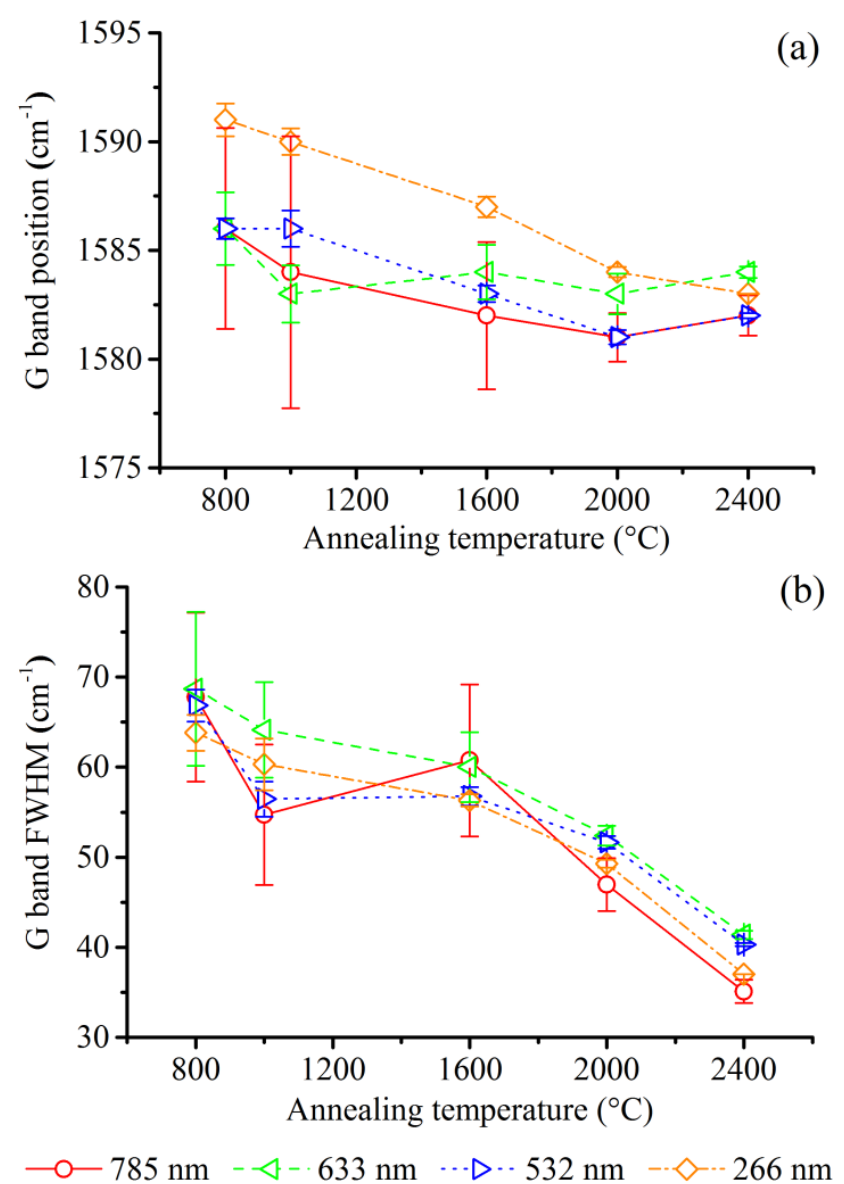

Fig. 6. Variation of $G$ band characteristics with annealing temperature for the four laser excitation wavelengths: (a) position; and (b) FWHM. The values for the base carbon are plotted for reference at the temperature where activation took place. Lines are a guide to the eye only.

Fig. 6(b) shows the variation of the $G$ band FWHM with annealing temperature; once again, within the uncertainty, no excitation energydependence is seen here. The FWHM does appear, however, to decrease along the annealing 
pathway, with the decrease accelerating beyond $1600^{\circ} \mathrm{C}$ towards a value that is around double that of graphite, which is $15 \mathrm{~cm}^{-1}$. As in-plane defects [24, 63] and small cluster size [22] are both known to broaden the $G$ band, these trends suggest the level of defects is decreasing and/or the lateral dimensions of the clusters are increasing along the annealing pathway, once again in keeping with the XRD results.

\subsubsection{D band}

Fig. 7 shows the variation of the $\mathrm{D}$ band position of all the carbons studied here with the laser excitation energy. This shows that, within the uncertainty of the data, the position of the D band remains unchanged along the annealing pathway. It does, however, vary with the excitation energy at a rate of $50 \mathrm{~cm}^{-1}$ per $\mathrm{eV}$, entirely in line with prior observations for pyrolytic carbons [43] and a PFA char carbonized at $600^{\circ} \mathrm{C}$ [31]. This confirms the validity of the spectra deconvolutions.

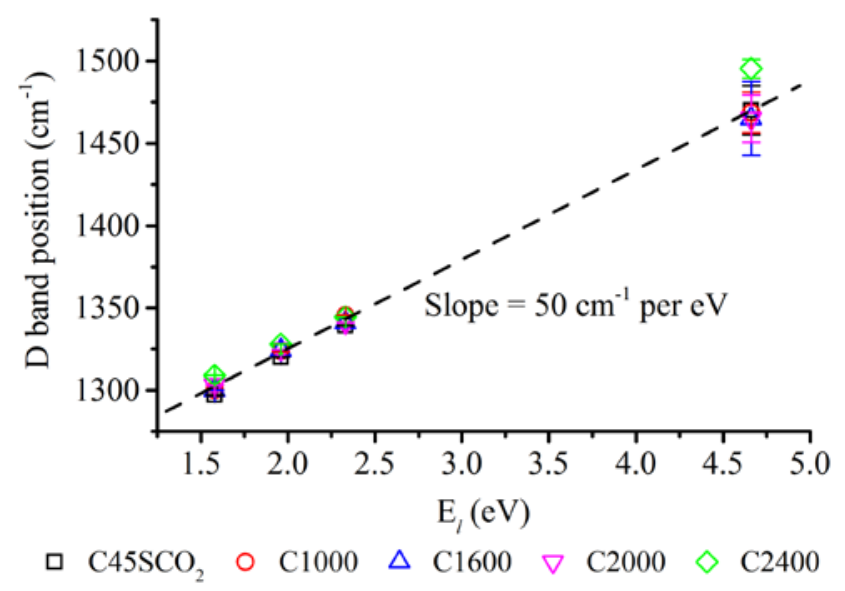

Fig. 7. Variation of $\mathrm{D}$ band position with excitation energy for the carbons.

\subsubsection{D' band}

The D' band, which is a defect-induced feature that can be explained by intra-valley double resonance scattering process [32], is observed in all carbons along the annealing pathway for all excitation energies. This is in line with previous observations for multi-crystalline graphite [30], nanographites [40, 41], defective graphenes [2426, 33, 34], soots [39], carbon blacks [31] and polymer derived carbons [31]. Fig. 8, which shows the variation of the D' band position of all the carbons considered here with excitation energy, indicates that this position is dispersive for $10 \mathrm{~cm}^{-1}$ per $\mathrm{eV}$, which is once again consistent with that observed previously [23, 32]. This once again supports the validity of the spectra deconvolutions presented here.

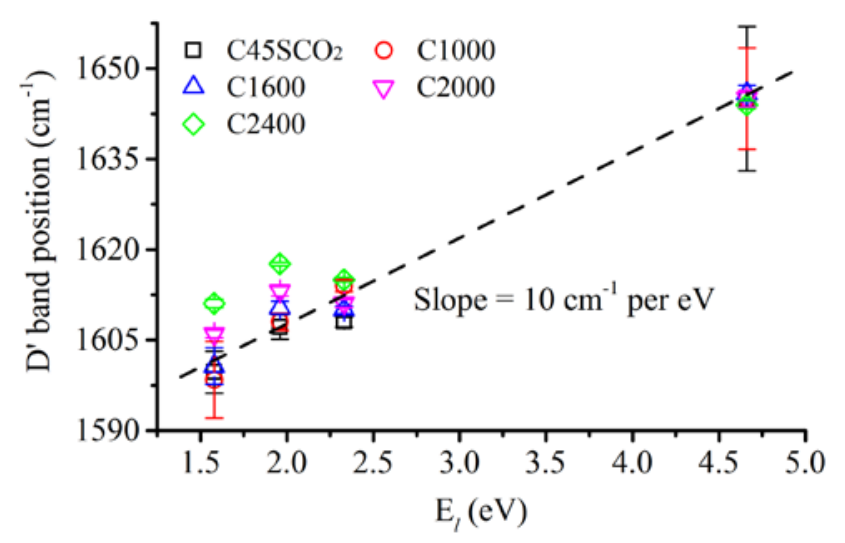

Fig. 8. Variation of $D^{\prime}$ band position with excitation energy for the carbons.

\subsubsection{A band}

The A band is observed for all the carbons excepting C2400 using the NIR and UV excitation. The presence of the A band here is consistent with previous observations for many types of disordered carbons, including carbon blacks [37], activated carbons [36], carbon onions [41], diamond like carbon films [35], ion- 
bombarded graphites [63] and graphenes [24]. Fig. 9(a), which shows the A band position against excitation energy, indicates the position falls within a narrow range $\left( \pm 30 \mathrm{~cm}^{-1}\right)$ of $1530 \mathrm{~cm}^{-1}$. As the variations are largely within uncertainty, the band position appears to be non-dispersive. Whilst this possibility has not been commented upon in the literature before, previous work on $\mathrm{Ar}^{+}$ion bombarded graphites [63] suggests that the A band might be a density of states feature (in common with the $G$ band), and thus a nondispersive character is not unexpected.
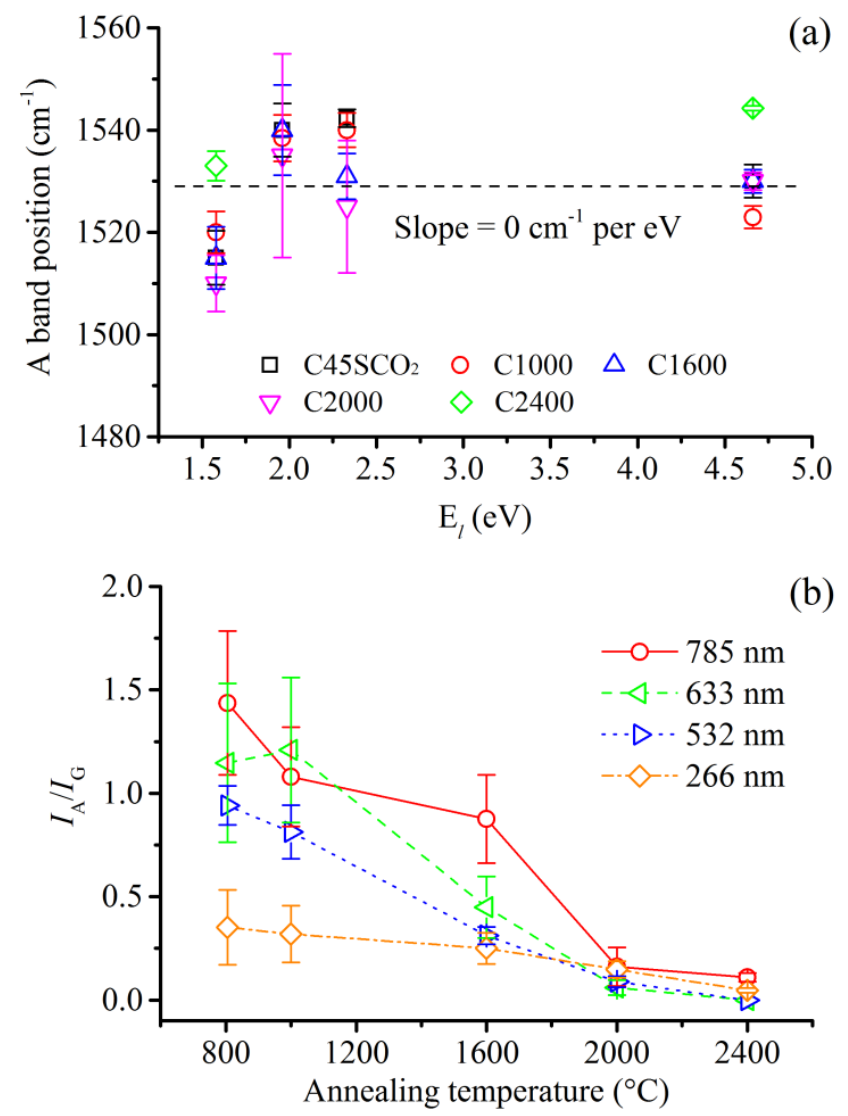

Fig. 9. Key characteristics of the A band: (a) A band position variation with excitation energy for the carbons; and (b) variation of $I_{\mathrm{A}} / I_{\mathrm{G}}$ ratio with annealing temperature for the four excitation wavelengths.

Fig. 9(b) shows the variation of the $I_{\mathrm{A}} / I_{\mathrm{G}}$ ratio along the annealing pathway for the four excitation wavelengths. This figure shows that the intensity ratio decreases along the annealing pathway, with the ratio for the non-UV excitation wavelengths decreasing by an order of magnitude between the base and C2400 carbon. The decrease is far smaller for the UV excitation, reflecting the ratio's clear excitation energy dependence. This suggests the A band cross section is energy dependent.

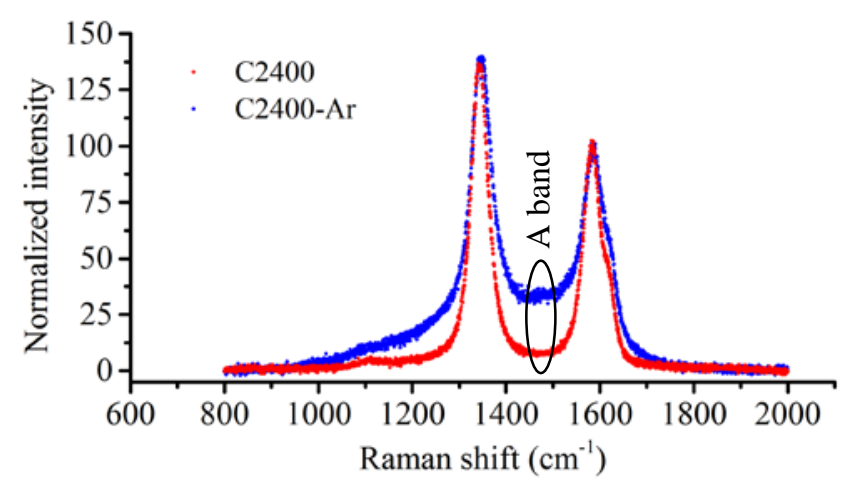

Fig. 10. Raman spectra of C2400 and C2400-Ar obtained using $532 \mathrm{~nm}$ excitation.

Two different types of defect have been posited as responsible for the $\mathrm{A}$ band. The first are $s p^{3}$ interstitial sites attached to the $s p^{2}$ network [3537]. The absence of any evidence of $s p^{3}$ sites in the carbons here (see discussion of the G band) suggests, however, that this origin is unlikely here. The second type of defect, which has been proposed based on a theoretical study, is $s p^{2}$ based point-like defects, in particular nonhexagonal rings [38], which are certainly known to exist in NPCs like those considered here [1214]. To test this possibility, the Raman spectrum of the C2400 carbon is compared in Fig. 10 to its $\mathrm{Ar}^{+}$ion bombarded counterpart, C2400-Ar. This shows that the bombardment leads to the reemergence of the A band when it had disappeared in the C2400 material. Based on the simulation of ion bombardment on graphene [64], it is thought 
that of the defects introduced by the ion bombardment used here, around 50\% will be single vacancies (SVs), with double vacancies (DVs) being less common, and Stone-Wales defects (SWs) very uncommon. Thus, it is proposed here that the A band is likely to be linked to SVs and DVs.

\subsubsection{TPA band}

The TPA band, which has been related to transpolyacetylene-like structures [42], is seen along the annealing pathway. Fig. 11(a), which shows the TPA band position variation with excitation energy for all the carbon samples, indicates it is energy dispersive. Whilst it is not unambiguous, the results in this figure suggest there may be two types of energy dependence. For $\mathrm{C}_{45 \mathrm{SCO}_{2}}$ and $\mathrm{C} 1000$, TPA band position shows a positive shift with excitation energy at a rate of $\sim 35 \mathrm{~cm}^{-1}$ per $\mathrm{eV}$. For the remaining samples, however, the TPA band position shifts in the opposite direction at the same rate. Such positive and negative shifts of the TPA band have been reported elsewhere for nanographites [40, 41] and diamond-like carbons [42], and hence the results here may have some basis in fact, but clearly more detailed study is required.

Fig. 11(b) shows the variation of the $I_{\mathrm{TPA}} / I_{\mathrm{G}}$ ratio along the annealing pathway. This figure shows that the intensity ratio decreases along the pathway for all the excitation wavelengths. However, unlike the A band, the TPA band remains present in all spectra right up to $2400^{\circ} \mathrm{C}$. This suggests that the transpolyacetylene-like structures in the carbon considered here are relatively resistant to annealing. The figure also shows that the $I_{\mathrm{TPA}} / I_{\mathrm{G}}$ ratio is influenced by the excitation energy. This is in part due to the substantial reduction in the $G$ band cross section at low energies, but an energy dependence of the TPA cross section may also play a role.
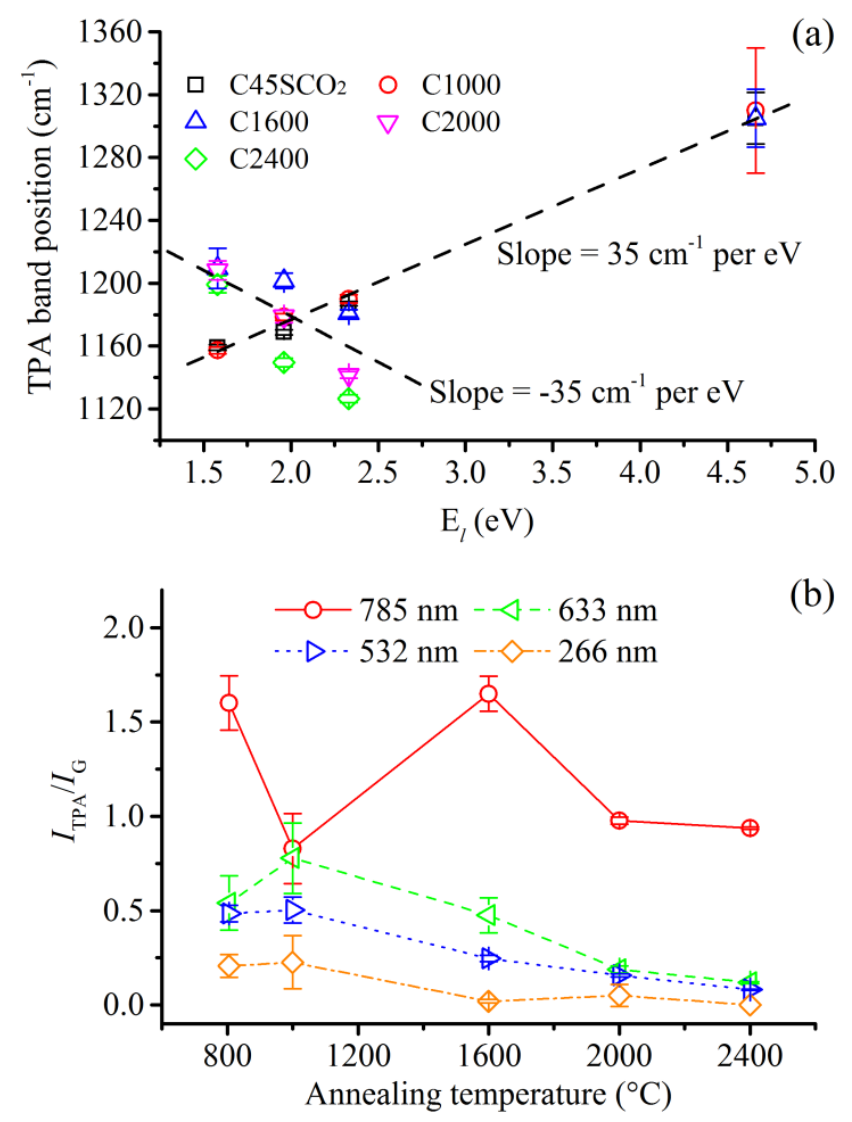

Fig. 11. Key characteristics of the TPA band: (a) TPA band position variation with excitation energy for the carbons; and (b) variation of $I_{\mathrm{TPA}} / I_{\mathrm{G}}$ ratio with annealing temperature for the four excitation wavelengths.

\section{3. $L_{a}$ and defect density from the $I_{D} / I_{G}$}

The pioneering work of Tuinstra and Koenig [20] showed that $I_{\mathrm{D}} / I_{\mathrm{G}}$ is inversely proportional to $L_{\mathrm{a}}$ in carbons of high graphitic content. More recent work on nanographites of controlled sizes ranging from 20 to $65 \mathrm{~nm}$ [22] suggested that the Tuinstra-Koenig relationship is in fact excitationenergy, $\mathrm{E}_{l}$, dependent as per 
$\left(I_{\mathrm{D}} / I_{G}\right)_{a}=\frac{C \mathrm{E}_{l}^{-4}}{L_{\mathrm{a}}}$

where $C$ is a constant, and we have assigned the $a$-subscript to the intensity ratio for a reason that will become clearer below. This excitation energy dependence, which is often termed the $\omega^{4}$ ( $\left.=2 \pi \mathrm{E}_{l} / h\right)$ dependence [65], originates from the energy dependence of the $G$ band scattering cross section [22]. Fig. 12, which shows the variation of $I_{\mathrm{D}} / I_{\mathrm{G}}$ against the inverse of the excitation energy for the carbons, indicates that the $\omega^{4}$ dependence indeed holds for the carbons obtained at the two higher annealing temperatures, C2000 and C2400. This dependence does not, however, appear to hold for the other carbons, suggesting that $\omega^{4}$ dependence is not applicable to materials whose structures are some way from being graphitic in nature. It is, therefore, proposed that the following more general form of Eq. (3) be

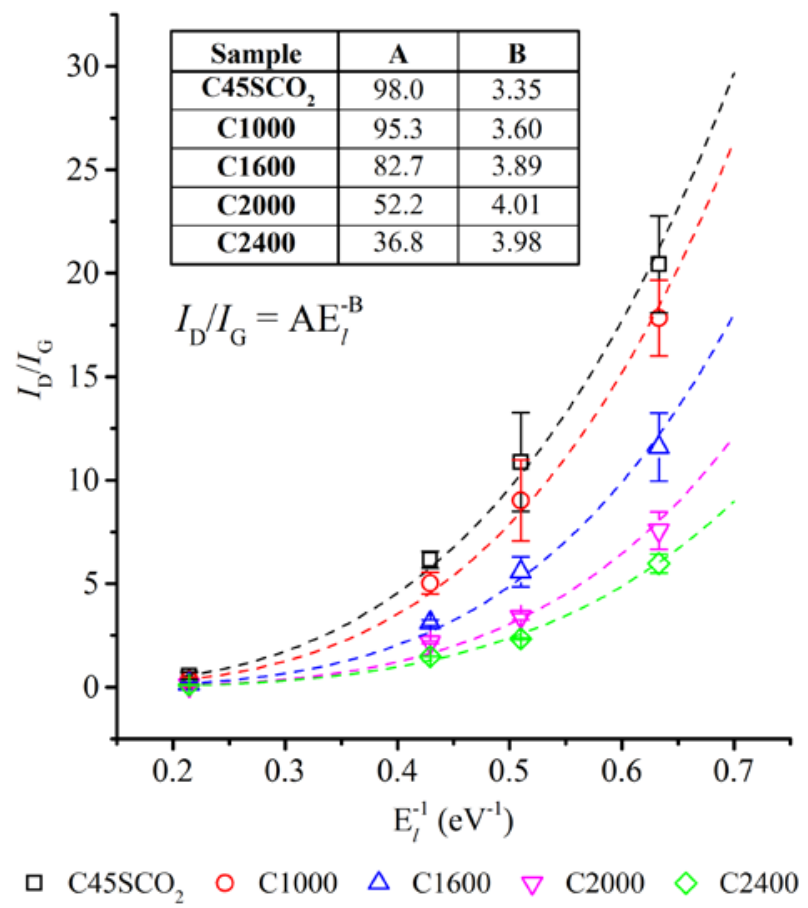

Fig. 12. Variation of the $I_{\mathrm{D}} / I_{G}$ ratio with inverse excitation energy. The parameters obtained by fitting Eq. (4) are shown in the inset table.
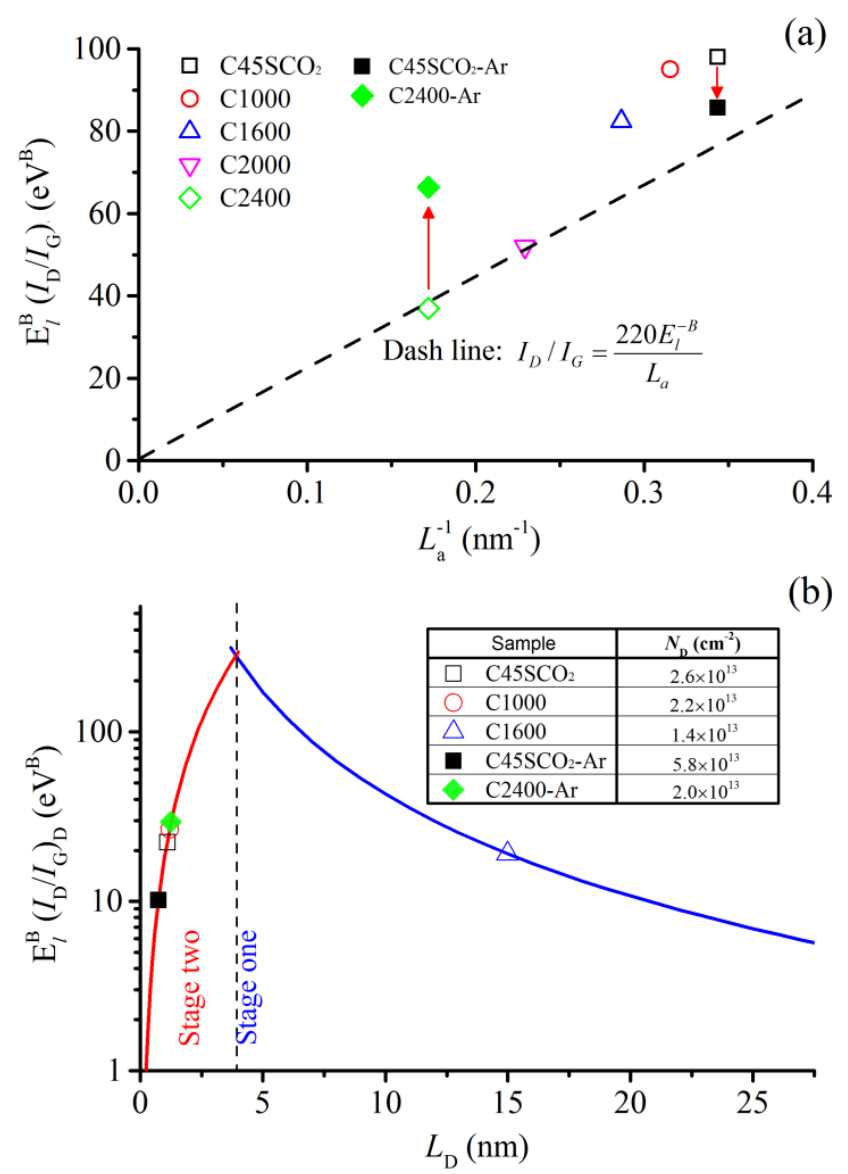

Fig. 13. Contribution to $I_{\mathrm{D}} / I_{\mathrm{G}}$ from $L_{\mathrm{a}}$ and $L_{\mathrm{D}}$. (a) plot of A values $\left(\mathrm{E}_{l}^{B}\left(I_{\mathrm{D}} / I_{G}\right)\right)$ against $L_{a}^{-1}$, (b) the locations of $\mathrm{C}_{4} 5 \mathrm{SCO}_{2}, \mathrm{C} 1000, \mathrm{C} 1600$, $\mathrm{C}_{45 \mathrm{SCO}_{2}} \mathrm{Ar}$ and $\mathrm{C} 2400-\mathrm{Ar}$ on the two-stage defect trajectory.

used for NPCs

$\left(I_{\mathrm{D}} / I_{G}\right)_{a}=\frac{C \mathrm{E}_{l}^{-B}}{L_{\mathrm{a}}}$

This equation suggests that plotting $\left(I_{\mathrm{D}} / I_{G}\right) \mathrm{E}_{l}^{B}$ against $\left(L_{\mathrm{a}}\right)^{-1}$ should collapse all the data for the carbons onto a single line. As Fig. 13(a) shows, this is indeed the case for the two most annealed carbons here, C2000 and C2400. The others, however, fall above the line defined by these two carbons. This suggests there is another factor at play. It is now known that the Raman D band is not only affected by the in-plane extent, $L_{a}$, but also in-plane defects [53]. The relationship between the $I_{\mathrm{D}} / I_{\mathrm{G}}$ ratio and point-like defects 
have been studied in recent years by considering graphenes modified by controlled ion bombardment [24-26, 33]. This work showed that $I_{\mathrm{D}} / I_{G}$ ratio is related to the average distance between nearest defects, $L_{\mathrm{D}}$ in a so called twostage trajectory. At low in-plane defects densities (stage one, i.e. large $L_{D}$ ), this dependency was found to be inversely proportional to the square of the inter-defect distance

$$
\left(I_{\mathrm{D}} / I_{G}\right)_{D}=\frac{(4.3) \times 10^{3}}{L_{\mathrm{D}}^{2}} \mathrm{E}_{l}^{-B}
$$

where the $\omega^{4}$ dependence observed in this prior work [25] has been replaced by the more general energy dependence observed here, and the $D$ subscript indicates the intensity ratio is related to the in-plane defects. At $L_{D}$ of around $3 \mathrm{~nm}$, this Stage One dependency was found to change to Stage Two [27, 60] (the more general power dependency has once again been used) to

$$
\left(I_{\mathrm{D}} / I_{G}\right)_{D}=18.5 \mathrm{E}_{l}^{-B} L_{\mathrm{D}}^{2}
$$

Returning to Fig. 13(a), on the basis that the three less-annealed carbons appear to fall on a roughly straight line parallel to the line that passes through the C2000 and C2400 carbons, it is proposed here that the ratio of the intensities of the $\mathrm{D}$ and $\mathrm{G}$ bands be composed of two parts as per

$I_{\mathrm{D}} / I_{G}=\left(I_{\mathrm{D}} / I_{G}\right)_{a}+\left(I_{\mathrm{D}} / I_{G}\right)_{D}$

Using this equation with Eq. (4) for $\left(I_{\mathrm{D}} / I_{G}\right)_{a}$ allows evaluation of the defect component, $\left(I_{\mathrm{D}} / I_{G}\right)_{D}$. Comparing it with the two-stage trajectory as expressed in Eq. (5) and (6) yields Fig. 13(b) This is further supported by the results obtained from the Ar-ion bombarded versions of the ${\mathrm{C} 45 \mathrm{SCO}_{2}}_{2}$ and $\mathrm{C} 2400$ carbon, which are also shown in Fig. 13.

The defect density, $N_{\mathrm{D}}$, can be evaluated given $L_{\mathrm{D}}$ using

$N_{\mathrm{D}}\left(\mathrm{cm}^{-2}\right)=\frac{10^{14}}{\pi L_{\mathrm{D}}^{2}}$

Using this equation yields the defect densities in the inset table of Fig. 13(b). This table suggests that the in-plane defect density in the C1600 carbon is approximately half that of the base carbon, and the Ar-ion bombardment that the base carbon was subject to roughly doubled the defect density.

\subsection{Defect evolution along the annealing pathway}

The structural evolution along the annealing pathway studied here can be broken up into two separate stages. As the analysis of the $I_{\mathrm{D}} / I_{G}$ ratio in the previous section showed, annealing up to somewhere below $1600^{\circ} \mathrm{C}$ sees a rapid removal of defects accompanied by a modest increase of in-plane extent. Above $1600^{\circ} \mathrm{C}$, however, this analysis suggests that growth of the in-plane extent accelerates. This analysis is further supported by the observed variation of the FWHM of the $\mathrm{G}$ band and $I_{\mathrm{A}} / I_{\mathrm{G}}$ ratio along the annealing pathway (see Fig. 6 and Fig. 10 respectively), as well as the XRD analysis (see Fig. 3). Support for this proposed mechanism can also be found from an annealing study of a phenolic resin based carbon [6], which is also non-graphitizing, where they observed a rapid growth of $L_{\mathrm{a}}$ using XRD between 1600 and $2500^{\circ} \mathrm{C}$. 
Whilst Raman analysis clearly does not elucidate the atomistic-level annealing process, processes can be conjectured that are consistent with the analysis and other results, including that based on molecular modelling. The two stage process observed here suggests the presence of at least two groups of defects. The first group are particularly mobile at lower temperatures, and are thus likely to be constituted by, for example, point defects such as Stones-Wales defects, single point vacancies, and out-of-plane atoms (e.g. those cross-linking between adjacent stacked planes) [66-68]. These will migrate at the lower annealing temperatures (between the $800^{\circ} \mathrm{C}$ at which the material is formed and $1600^{\circ} \mathrm{C}$ ) to form more stable structures, including higher order defects such as double vacancies [68]. The second group only become more mobile at higher temperatures, and are thus constituted by more complex defects. An example that may be relevant here are dislocation-like defects which, once removed, bring an increase of the in-plane extent.

\section{Conclusion}

The structural evolution of a PFA derived NPC along a thermal annealing pathway spanning from 1000 to $2400^{\circ} \mathrm{C}$ was studied using multiwavelength Raman spectroscopy. The spectra obtained were deconvoluted using G, D, D', A and TPA bands. The validity of the deconvolutions was verified through inspection of the residuals and, more importantly, the recovery of the expected dispersive character of the various bands.
Analysis of the A band suggests that it is associated with single- and double-point vacancies, such as 5- and 7-membered ring structures. There is clear support for this finding in the form of recent high resolution TEM images. The $\omega^{4}$ dependence of the $I_{\mathrm{D}} / I_{\mathrm{G}}$ ratio was found to be valid only for the upper end of the annealing pathway. Below this, the power of the excitation energy dependency decreased with decreasing annealing temperature.

The analysis here strongly suggests that the $I_{\mathrm{D}} / I_{\mathrm{G}}$ ratio is the sum of two parts: one inversely proportional to the in-plane extent of the graphitic crystallites, $L_{a}$, (i.e. the Tuinstra-Koenig type relationship), and a second that is related to the inter-defect distance, $L_{D}$ [24-27].

Finally, drawing on the Raman results collectively, it is proposed that the carbonaceous skeleton transforms during annealing via a two stage process. For the annealing temperature range up to somewhere below $1600^{\circ} \mathrm{C}$, removal of structural defects dominates, especially pointlike defects, whilst the crystallite size undergoes a mild increase. At temperatures beyond $1600{ }^{\circ} \mathrm{C}$, the rate of growth of the crystallites accelerates substantially. This mechanism is supported by $\mathrm{XRD}$ analysis along the annealing pathway.

There is room for further study of the transformations observed here. For example, there is a clear need to consider the transformations below $1600{ }^{\circ} \mathrm{C}$ with a higher degree of resolution (e.g. every $100^{\circ} \mathrm{C}$ ) and with further techniques such as X-ray and UV photoelectron spectroscopy in the hope to better 
understand the in-plane defect evolution in carbons prepared below $1600{ }^{\circ} \mathrm{C}$.

\section{Acknowledgements}

$\mathrm{CH}$ acknowledges a joint scholarship provided by China Scholarship Council (CSC) and the University of Adelaide. SS acknowledges the award of International Postgraduate Research Scholarship (IPRS) from the University of Adelaide. The support of the Australian Research Council's Discovery Program (DP110101293) and Linkage Infrastructure, Equipment and Facilities Program (LE130100119) is also gratefully acknowledged.

\section{References}

[1] Bandosz T, Biggs M, Gubbins K, Hattori Y, Iiyama T, Kaneko K, et al. Molecular models of porous carbons. In: Radovic L, editor. Chemistry and Physics of Carbon, Vol 28, New York: Marcel Dekker; 2003 p. 41-228.

[2] Oberlin A. Carbonization and graphitization. Carbon 1984; 22(6):521-41.

[3] Oberlin A, Villey M, Combaz A. Influence of elemental composition on carbonization: Pyrolysis of kerosene shale and kuckersite. Carbon 1980; 18(5):347-53.

[4] Franklin RE. Crystallite growth in graphitizing and non-graphitizing carbons. Proc Roy Soc A 1951; 209(1097):196-218.

[5] Petkov V, Difrancesco RG, Billinge SJL, Acharya M, Foley HC. Local structure of nanoporous carbons. Philos Mag B 1999; 79(10):1519-30.

[6] Zhang Z-l, Brydson R, Aslam Z, Reddy S, Brown A, Westwood A, et al. Investigating the structure of non-graphitising carbons using electron energy loss spectroscopy in the transmission electron microscope. Carbon 2011; 49(15):5049-63.

[7] Dmowski W, Contescu CI, Llobet A, Gallego NC, Egami T. Local atomic density of microporous carbons. J Phys Chem C 2011; 116(4):2946-51.

[8] Hawelek L, Brodka A, Dore JC, Honkimäki V, Burian A. Fullerene-like structure of activated carbons. Diamond Relat Mater 2008; 17(710):1633-8.

[9] Hawełek L, Kołoczek J, Bródka A, Dore JC, Honkimäki V, Burian A. Structural studies of disordered carbons by high-energy X-ray diffraction. Philos Mag 2007; 87(32):4973-86.

[10] Smith MA, Foley HC, Lobo RF. A simple model describes the PDF of a non-graphitizing carbon. Carbon 2004; 42(10):2041-8.

[11] Harris PJF. New perspectives on the structure of graphitic carbons. Crit Rev Solid State Mater Sci 2005; 30(4):235-53.

[12] Harris PF. Fullerene-like models for microporous carbon. J Mater Sci 2013; 48(2):565-77.

[13] Harris PJF, Liu Z, Suenaga K. Imaging the atomic structure of activated carbon. J Phys: Condens Matter 2008; 20(36).

[14] Guo J, Morris JR, Ihm Y, Contescu CI, Gallego NC, Duscher G, et al. Topological defects: Origin of nanopores and enhanced adsorption performance in nanoporous carbon. Small 2012; 8(21):3283-8.

[15] Farmahini AH, Opletal G, Bhatia SK. Structural modelling of silicon carbide-derived nanoporous carbon by hybrid reverse monte carlo simulation. J Phys Chem C 2013; 117(27):1408194.

[16] Powles RC, Marks NA, Lau DWM. Selfassembly of $s p^{2}$-bonded carbon nanostructures from amorphous precursors. Phys Rev B 2009; 79(7):075430.

[17] Balandin AA. Thermal properties of graphene and nanostructured carbon materials. Nat Mater 2011; 10(8):569-81.

[18] Biniak S, Swiatkowski A, Pakula M. Electrochemical studies of penimena at active carbon-electrolyte solution. In: Radovic L, editor. Chemistry and Physics of Carbon, Vol 27, New York: Marcel Dekker; 2003 p. 125-226.

[19] Valeri P, Adam T, John C, Yang R. Li insertion in ball-milled graphitic carbon studied 
by total X-ray diffraction. J Phys: Condens Matter 2011; 23(43):435003.

[20] Tuinstra F, Koenig JL. Raman spectrum of graphite. J Chem Phys 1970; 53(3):1126-30.

[21] Cançado LG, Takai K, Enoki T, Endo M, Kim YA, Mizusaki $\mathrm{H}$, et al. General equation for the determination of the crystallite size $L_{a}$ of nanographite by Raman spectroscopy. Appl Phys Lett 2006; 88(16):163106.

[22] Cançado LG, Jorio A, Pimenta MA. Measuring the absolute Raman cross section of nanographites as a function of laser energy and crystallite size. Phys Rev B 2007; 76(6):064304.

[23] Pimenta MA, Dresselhaus G, Dresselhaus MS, Cancado LG, Jorio A, Saito R. Studying disorder in graphite-based systems by Raman spectroscopy. Phys Chem Chem Phys 2007; 9(11):1276-90.

[24] Lucchese MM, Stavale F, Ferreira EHM, Vilani C, Moutinho MVO, Capaz RB, et al. Quantifying ion-induced defects and Raman relaxation length in graphene. Carbon 2010; 48(5):1592-7.

[25] Cançado LG, Jorio A, Ferreira EHM, Stavale F, Achete CA, Capaz RB, et al. Quantifying defects in graphene via Raman spectroscopy at different excitation energies. Nano Lett 2011; 11(8):3190-6.

[26] Hang S, Moktadir Z, Mizuta H. Raman study of damage extent in graphene nanostructures carved by high energy helium ion beam. Carbon 2014; 72(0):233-41.

[27] Ferrari AC, Basko DM. Raman spectroscopy as a versatile tool for studying the properties of graphene. Nat Nano 2013; 8(4):235-46.

[28] Doyle TE, Dennison JR. Vibrational dynamics and structure of graphitic amorphous carbon modeled using an embedded-ring approach. Phys Rev B 1995; 51(1):196-200.

[29] Saito R, Jorio A, Souza Filho AG, Grueneis A, Pimenta MA, Dresselhaus G, et al. Dispersive Raman spectra observed in graphite and single wall carbon nanotubes. Physica B 2002; 323(14):100-6.

[30] Tsu R, González H J, Hernández C I. Observation of splitting of the $E_{2 \mathrm{~g}}$ mode and twophonon spectrum in graphites. Solid State Commun 1978; 27(5):507-10.
[31] Wang Z, Huang X, Xue R, Chen L. Dispersion effects of Raman lines in carbons. J Appl Phys 1998; 84(1):227-31.

[32] Saito R, Jorio A, Souza Filho AG, Dresselhaus G, Dresselhaus MS, Pimenta MA. Probing phonon dispersion relations of graphite by double resonance raman scattering. Phys Rev Lett 2001; 88(2):027401.

[33] Eckmann A, Felten A, Mishchenko A, Britnell L, Krupke R, Novoselov KS, et al. Probing the nature of defects in graphene by raman spectroscopy. Nano Lett 2012; 12(8):392530.

[34] Eckmann A, Felten A, Verzhbitskiy I, Davey R, Casiraghi C. Raman study on defective graphene: Effect of the excitation energy, type, and amount of defects. Phys Rev B 2013; 88(3):035426.

[35] Yoshikawa M, Katagiri G, Ishida H, Ishitani A, Akamatsu T. Raman spectra of diamondlike amorphous carbon films. J Appl Phys 1988; 64(11):6464-8.

[36] Cuesta A, Dhamelincourt P, Laureyns J, Martínez-Alonso A, Tascón JMD. Raman microprobe studies on carbon materials. Carbon 1994; 32(8):1523-32.

[37] Jawhari T, Roid A, Casado J. Raman spectroscopic characterization of some commercially available carbon black materials. Carbon 1995; 33(11):1561-5.

[38] Dallas TEJ. Structural phases of disordered carbon materials. Texas Tech Univ, PhD thesis, 1996.

[39] Sadezky A, Muckenhuber H, Grothe H, Niessner R, Pöschl U. Raman microspectroscopy of soot and related carbonaceous materials: Spectral analysis and structural information. Carbon 2005; 43(8):1731-42.

[40] Osipov VY, Baranov AV, Ermakov VA, Makarova TL, Chungong LF, Shames AI, et al. Raman characterization and UV optical absorption studies of surface plasmon resonance in multishell nanographite. Diamond Relat Mater 2011; 20(2):205-9.

[41] Bogdanov K, Fedorov A, Osipov V, Enoki T, Takai K, Hayashi T, et al. Annealing-induced structural changes of carbon onions: High- 
resolution transmission electron microscopy and Raman studies. Carbon 2014; 73(0):78-86.

[42] Ferrari AC, Robertson J. Origin of the 1150 $\mathrm{cm}^{-1}$ Raman mode in nanocrystalline diamond. Phys Rev B 2001; 63(12):121405.

[43] Vidano RP, Fischbach DB, Willis LJ, Loehr TM. Observation of Raman band shifting with excitation wavelength for carbons and graphites. Solid State Commun 1981; 39(2):341-4.

[44] $\mathrm{Hu} \mathrm{C}$, Sedghi S, Madani SH, SilvestreAlbero A, Sakamoto H, Kwong P, et al. Control of the pore size distribution and its spatial homogeneity in particulate activated carbon. Carbon 2014; 78(0):113-20.

[45] Biscoe J, Warren BE. An X-ray study of carbon black. J Appl Phys 1942; 13(6):364-71.

[46] Marsh H, Rodríguez-Reinoso F. Activated Carbon. Oxford: Elsevier Science Ltd; 2006.

[47] Seber GAF, Wild CJ. Nonlinear Regression. Hoboken, New Jersey: John Wiley \& Sons, Inc; 2003.

[48] Bevington PR, Robinson DK. Data Reduction and Error Analysis for the Physical Sciences. 3rd ed. New York: McGraw-Hill; 2003.

[49] Burket CL, Rajagopalan R, Foley HC. Overcoming the barrier to graphitization in a polymer-derived nanoporous carbon. Carbon 2008; 46(3):501-10.

[50] Burket CL, Rajagopalan R, Marencic AP, Dronvajjala K, Foley HC. Genesis of porosity in polyfurfuryl alcohol derived nanoporous carbon. Carbon 2006; 44(14):2957-63.

[51] Wang Y, Alsmeyer DC, McCreery RL. Raman spectroscopy of carbon materials: structural basis of observed spectra. Chem Mater 1990; 2(5):557-63.

[52] Ferrari AC, Robertson J. Resonant Raman spectroscopy of disordered, amorphous, and diamondlike carbon. Phys Rev B 2001; 64(7):075414.

[53] Dresselhaus MS, Jorio A, Souza Filho AG, Saito R. Defect characterization in graphene and carbon nanotubes using Raman spectroscopy. Phil Trans R Soc A 2010; 368(1932):5355-77.

[54] Kim C, Yang K, Kim YJ, Endo M. Heat treatment temperature effects on structural and electrochemical properties of PVDC-based disordered carbons. J Mater Sci 2003; 38(13):2987-91.

[55] Burian A, Daniel P, Duber S, Dore J. Raman scattering studies of the graphitization process in anthracene- and saccharose-based carbons. Philos Mag B 2001; 81(5):525-40.

[56] Gruber T, Zerda TW, Gerspacher M. Raman studies of heat-treated carbon blacks. Carbon 1994; 32(7):1377-82.

[57] Shimodaira N, Masui A. Raman spectroscopic investigations of activated carbon materials. J Appl Phys 2002; 92(2):902-9.

[58] Rao AM, Fung AWP, Dresselhaus MS, Endo M. Structural characterization of heat-treated activated carbon fibers. J Mater Res 1992; 7(07):1788-94.

[59] Vázquez-Santos MB, Geissler E, László K, Rouzaud J-N, Martínez-Alonso A, Tascón JMD. Comparative XRD, Raman, and TEM study on graphitization of PBO-derived carbon fibers. J Phys Chem C 2011; 116(1):257-68.

[60] Ferrari AC, Robertson J. Interpretation of Raman spectra of disordered and amorphous carbon. Phys Rev B 2000; 61(20):14095-107.

[61] Casiraghi C, Ferrari AC, Robertson J. Raman spectroscopy of hydrogenated amorphous carbons. Phys Rev B 2005; 72(8):085401.

[62] Ferrari AC, Libassi A, Tanner BK, Stolojan V, Yuan J, Brown LM, et al. Density, $s p^{3}$ fraction, and cross-sectional structure of amorphous carbon films determined by x-ray reflectivity and electron energy-loss spectroscopy. Phys Rev B 2000; 62(16):11089-103.

[63] Jorio A, Lucchese MM, Stavale F, Achete CA. Raman spectroscopy study of $\mathrm{Ar}^{+}$ bombardment in highly oriented pyrolytic graphite. Phys Status Solidi B 2009; 246(1112):2689-92.

[64] Lehtinen O, Kotakoski J, Krasheninnikov AV, Tolvanen A, Nordlund K, Keinonen J. Effects of ion bombardment on a twodimensional target: Atomistic simulations of graphene irradiation. Phys Rev B 2010; 81(15):153401.

[65] Loudon R. The Raman effect in crystals. Adv Phys 2001; 50(7):813-64. 
[66] Li L, Reich S, Robertson J. Defect energies of graphite: Density-functional calculations. Phys Rev B 2005; 72(18):184109.

[67] El-Barbary AA, Telling RH, Ewels CP, Heggie MI, Briddon PR. Structure and energetics of the vacancy in graphite. Phys Rev B 2003; 68(14):144107.

[68] Banhart F, Kotakoski J, Krasheninnikov AV. Structural defects in graphene. ACS Nano 2010; 5(1):26-41. 